\title{
Auslegungsmethodik und Ultra-Vires-Kontrolle
}

VB verfassungsblog.de/auslegungsmethodik-und-ultra-vires-kontrolle/

Hanno Kube Fr 5 Jul 2013

Wurde im Zuge der Eurokrise gegen das Bail-out-Verbot des Art. 125 Abs. 1 AEUV verstoßen oder nicht? Erlaubt Art. 123 Abs. 1 AEUV der EZB in der gegenwärtigen Situation, Staatsanleihen von Krisenstaaten auf dem Sekundärmarkt zu kaufen? Kann die direkte Bankenfinanzierung durch den ESM auf die Befugnis des Gouverneursrats gestützt werden, die Liste der Finanzhilfeinstrumente zu ergänzen (Art. 19 ESM-Vertrag)?

All diese Fragen betreffen die Auslegung europa- bzw. völkerrechtlicher Verträge, insbesondere durch die Gerichte. Der EuGH hat Art. 125 Abs. 1 AEUV in der Pringle-Entscheidung sehr stark teleologisch interpretiert und dabei, zugespitzt formuliert, von einem Haftungsverbot in ein Solidaritätsgebot umgeformt. In Art. 123 Abs. 1 AEUV soll es dagegen, nach Auffassung derer, die eine weite Kompetenz der EZB sehen, vor allem auf den Wortlaut der Vorschrift ankommen, der Käufe auf dem Primär-, nicht auf dem Sekundärmarkt untersagt. Im Zusammenhang des ESM-Vertrags rückt in jedem Fall die Frage nach der Bedeutung von Systematik und Entstehungsgeschichte in den Vordergrund, weil die Norm des Art. 19 ESM-Vertrag, die zur Erweiterung des Instrumentenkastens der Hilfe ermächtigt, am Ende einer Liste ausdrücklich benannter Finanzhilfeinstrumente steht, die alle den Staatshaushalt als Adressaten der Hilfeleistung vorsehen, also defizitwirksam sind.

Sehr viel stärker als bislang sollte angesichts all dessen über Auslegungsmethodik in der europäischen Rechtsgemeinschaft gesprochen werden. Eine bessere Verständigung darüber, wie europa- und (europa)völkerrechtliche Verträge auszulegen sind, woran sich also die anderen Vertragsparteien erwartbarerweise festhalten lassen müssen, könnte die institutionellen, vor allem gerichtlichen Konflikte, die sich insoweit auftun, jetzt und vor allem in Zukunft mildern. Neben den klassischen Auslegungskriterien im Sinne Savignys kommen dabei auch die Auslegungsregeln des Völkerrechts, an erster Stelle die Regeln der Wiener Vertragsrechtskonvention (Art. $31 \mathrm{ff}$. WVRK), in Betracht.

Diese Kriterien und Regeln könnten auch das Prüfungsprogramm des Bundesverfassungsgerichts bereichern. Staatenübergreifenden Einbindungen begegnet das Bundesverfassungsgericht seit langem durch Zugeständnisse im grundrechtlichen Prüfungsmaßstab, im europäischen Zusammenhang durch die fortgeschriebene Solange IIDogmatik. Zur Umsetzung der Schrankenregelung in Art. 23 Abs. 1 Satz 3 GG sind die ultra vires-Prüfung nach der Honeywell-Doktrin (ersichtliche, erheblich ins Gewicht fallende Kompetenzüberschreitung) und die Frage nach einer sonstigen Berührung der Verfassungsidentität (insbesondere durch Aushöhlung des Budgetrechts) hinzugetreten.

Um im Rahmen der ultra vires-Prüfung über eine Kompetenzüberschreitung befinden zu können, ist im ersten Schritt zu fragen, welche Kompetenzen tatsächlich übertragen worden sind. Die Beantwortung dieser Frage, die in besonderer Weise auf europaweite Konsistenz angewiesen ist, könnte durch die Heranziehung der genannten Auslegungsregeln erleichtert werden.

Anstatt sich auf unverfügbare materielle, dabei aber einseitig definierte Maßstäbe zurückzuziehen (Zurückbleiben des europäischen Grundrechtsstandards hinter dem deutschen Grundrechtsstandard; Schwelle der erheblich ins Gewicht fallenden Kompetenzüberschreitung), könnte das Bundesverfassungsgericht damit dem für das Kompetenzrecht typischen und zutreffenden Denken in klaren und eindeutigen, nicht abwägungsfähigen Abgrenzungen treu bleiben, zugleich aber der internationalen, auf Ebene der Vertragsinterpretation Zugeständnisse verlangenden Dimension der streitgegenständlichen Kompetenzregelung Rechnung tragen. Ergibt sich danach, also unter Berücksichtigung der europa- und völkervertragsrechtlichen Auslegungsstandards, eine Kompetenzüberschreitung, sollte das Bundesverfassungsgericht diese dann umso selbstbewusster feststellen.

Kompetenzverlagernde Normen lassen sich dadurch in einer Weise interpretieren, die sich das 
Bundesverfassungsgericht wie auch der EuGH zu eigen machen kann. Dies könnte den Gedanken der Kooperation der Gerichte mit neuem Leben erfüllen.

LICENSED UNDER CC BY NC ND

SUGGESTED CITATION Kube, Hanno: Auslegungsmethodik und Ultra-Vires-Kontrolle, VerfBlog, 2013/7/05, http://verfassungsblog.de/auslegungsmethodik-und-ultra-vires-kontrolle/. 